Syntax Literate : Jurnal Ilmiah Indonesia p-ISSN: 2541-0849

e-ISSN : 2548-1398

Vol. 4, No. 12 Desember 2019

\title{
PERANCANGAN WEBSITE E-COMMERCE SEBAGAI MEDIA PENJUALAN MINIATUR BUS
}

\section{Dedi Saputra, Riswandi Ishak dan Setiaji}

Fakultas Teknologi Informasi Universitas Bina Sarana Informatika

Email: dedi.dst@bsi.ac.id,riswandi.rik@bsi.ac.id dan setiaji.sej@bsi.ac.id

\begin{abstract}
Abstrak
Kemampuan ilmu komunikasi dan komputer saat ini memang diperlukan oleh semua manusia. Seperti perkembangan teknologi saat ini yang sedang berkembang, khususnya komputer dan internet, sehingga menjadikan sebagai salah satu sumber media informasi dan telekomunikasi, terutama untuk mendapatkan informasi yang cepat, akurat, dan up to date pada saat ini. Dengan pemanfaat kemajuan teknologi saai ini, pemasaran produk apapun dapat dilakukan. Perancangan website e-commerce sangat cocok untuk memasarkan produk agar dapat meningkatkan penjualan. Oleh karena itu penulis mencoba merancang sebuah web c-commerce penjualan miniatur bus yang dapat memberikan informasi berbasis web. Perancang website ini penulis buat untuk memperkenalkan produk yang di tawarkan, mempermudah customer dalam memesan produk yang akan dibeli dan informasi perusahaan melalui internet. Dengan adanya website ini diharapkan dapat memiliki manfaat bagi perusahaan agar berjalan lebih efektif dan efesien serta memberikan informasi bagi pelanggan dan pengguna internet secara lebih cepat.
\end{abstract}

Kata Kunci: Website, E-Commerce, Sistem Informasi

\section{Pendahuluan}

Informasi menjadi sebuah kebutuhan yang pokok, agar dapat terus memperbaharui biasanya mencari dan mendapatkannya melalui media cetak, elektronik dan internet. Seperti halnya makhluk hidup yang membutuhkan makan, maka informasi juga sudah menjadi kewajiban untuk segera dipenuhi, jika tidak terpenuhi maka bisa berpengaruh buruk bagi penggunanya. Di antara media yang telah disebutkan, internet menjadi sebuah alternatif pilihan yang tepat untuk mendapatkan data yang dibutuhkan dengan mudah dan cepat (Pramadita, 2017).

Penjualan Miniatur Bus saat ini sangat di minati oleh pecinta bus di Indonesia, selain bentuknya yang beraneka ragam aksesoris yang terdapat pada miniatur bus tersebut juga menyerupai dengan bus yang aslinya, harganya pun terjangkau untuk kalangan komunitas pecinta bus di Indonesia. Terbatasnya ruang lingkup pemasaran 
produk yang hanya berada di lingkungan sekitar saja, menjadikan salah satu faktor utama permasalahan pada penjual. Untuk itu pemilik mesti lebih kreatif untuk mengembangkan produk miniatur bus tersebut, perlu adanya meningkatkan pelayanan yang lebih optimal terhadap pelanggan.

Kehadiran internet tidak bisa dilepaskan dari kisah perang dingin antara Uni Soviet dengan Amerika serikat yang ingin menguasai dunia. Alkisah, Uni Soviet telah berhasil meluncurkan Sputnik keluar angkasa (Cahyono, 2016). Peluncuran sputnik ditunjukan untuk menggambarkan kepada dunia bahwa Uni Soviet memiliki teknologi yang sangat canggih. Amerika yang dimasa perang dingin merupakan musuh bebuyutan Uni Soviet pun tidak tinggal diam melihat pertunjukan teknologi tinggi milik Uni Soviet tersebut. Penggunaan internet sebagai media perdagangan terus meningkat dari tahun ke tahun, hal ini disebabkan karena manfaat kemudahan yang di dapat oleh perusahaan ataupun konsumen dengan melakukan transaksi di internet. Menurut (Manan, SH, \& Hum, 2017) "internet adalah sebuah teknologi yang bisa memberikan informasi pendahuluan yang perlu diketahui sebagai pengantar dunia internet. Internet awalnya digunakan untuk keperluan militer hingga akhirnya menjadi massal untuk keperluan sipil dan hiburan".

Keberadaan E-commerce merupakan alternatif bisnis yang cukup menjanjikan untuk diterapkan saat ini, karena E-commerce banyak memberikan kemudahan bagi kedua belah pihak, baik dari pihak penjual (merchant) atau dari pihak pembeli (buyer) dalam melakukan transaksi perdagangan meskipun tidak saling bertemu langsung atau berada dalam jarak yang sangat jauh (Ellyani \& Sari, 2016). Salah satu manfaat Ecommerce ini adalah dengan menekan biaya-biaya untuk prnjualan, karena perusahaan atau pedagang tidak perlu lagi memajang barang dagangan di etalase atau di toko, sedangkan di sisi pembeli, mereka tidak perlu keluar rumah untuk membeli barang yang di inginkan, hanya cukup membuka perangkat yang terhubung di internet dan mulai memilih-milih barang yang di inginkan. Menurut (Sutarman, n.d.) "E-commerce adalah singkatan dari Electronik Commerce, yaitu pembelian, penjualan dan pertukaran barang atau layanan dan informasi secara elektronik, yaitu melalui jaringan komputer terutama internet". E-commerce dapat diartikan dengan sangat luas, tidak hanya pembelian atau penjualan barang, tetapi juga layanan terhadap pelanggan, kerja sama dengan rekan bisnis serta membangun transaksi secara elektronik antara organisasi. 
Berbelanja atau melakukan transaksi di internet sangatlah berbeda dengan melakukan transaksi perdagangan di dunia nyata. Dengan E-commerce memungkinkan kita bertransaksi dengan cepat dan biaya yang sangat murah tanpa proses yang berbelitbelit, dimana pihak pembeli cukup melihat ketentuan-ketentuan yang disyaratkan oleh penjual (term of condition), apabila syarat dan ketentuan tersebut telah disetujui oleh pembeli, maka pembeli hanya memilih barang yang ditawarkan oleh penjual, dan klik beli, dan setelah pembeli membayar sejumlah uang yang tertera baik melalui transfer bank, mengirim bukti transfer ke web lalu si pembeli hanya menunggu barang yang di pesannya datang ke alamat yang sebelumnya telah di sertakan pada saat memesan barang.

\section{Metode Penelitian}

Dalam hal ini peneliti menggunakan metode deskriptif dengan membagi kedalam dua metode penelitian yang akan digunakan, yaitu: metode yang digunakan pada pengembangan perangkat lunak ini menggunakan model waterfall dan metode Pengumpulan Data

Untuk memperoleh data-data yang menunjang dalam menggunakan landasan teori dan konsep-konsep yang berkaitan dengan pembahasan ini, diantaranya :

1. Observasi

Aktifitas yang melakukan pengamatan terhadap suatu proses atau objek, dengan maksud memahami pengetahuan dari sebuah fenomena penjualan miniatur bus mulai dari pemesanan, pembayaran dan pengiriman barang. Berdasarkan gagasan yang sudah diketahui sebelumnya, penulis melakukan observasi di salah satu tempat pembuatan miniatur bus, dibikin berskala 1:50 berbahan fiber resin seat atau kursi di dalamnya juga berbahan fiber resin,mika \& ban karet/fibber. Miniatur bus yang sudah siap jual, di jual dengan harga Rp.350.000 persatuannya .

2. Kepustakaan

Studi Pustaka yang merupakan metode pengambilan data dari beberapa buku cetak yang ada, seperti buku yang ada di perpustakaan luar ataupun perpustakaan Akademi Manajemen Informatika dan Komputer Bina Sarana Informatika sebagai acuan mengenai pembuatan web berbasis $e$-commerce. 
Dedi Saputra, Riswandi dan Setiaji

\section{Hasil dan Pembahasan}

\section{A. Analisa Perancangan Website}

\section{Analisa Kebutuhan}

Dalam sebuah sistem web biasanya terdapat analisa kebutuhan dimana hal tersebut dibutuhkan agar nantinya terdapat alur yang jelas dalam perencanaan didalam sistem tersebut. Berikut analisa kebutuhan yang diperlukan

\section{a. Halaman Admin}

1) Admin dapat melakukan login

2) Admin dapat menambahkan, mengedit, menghapus data Produk

3) Admin dapat menambahkan, mengedit, menghapus data News

4) Admin dapat menambahkan, mengedit, menghapus data Download laporan.

5) Admin dapat melihat data laporan

\section{b. Halaman Pelanggan}

1) User dapat mengisi Form isi data member pelanggan

2) Pelanggan dapat Login Akses

3) Pelanggan dapat memesan serta membeli produk

4) Pelanggan dapat melakukan konfirmasi pembayaran Transaksi

5) Pelanggan dapat melakukan testimoni setelah barang sudah sampai di tangan pembeli.

\section{Perancangan perangkat lunak}

Dalam hal ini penulis akan menggambarkan rancangan website yang akan dibuat, yaitu mengenai bentuk layout maupun fungsinya yang nantinya dapat membantu dalam tahap perancangan website penjualan miniatur bus online. Berikut beberapa sampel layout yang penulis buat : 
a. Rancangan Antar Muka

1) Rancangan Antar Muka Login Admin

Gambar 1

Rancangan Antar Muka Login Admin

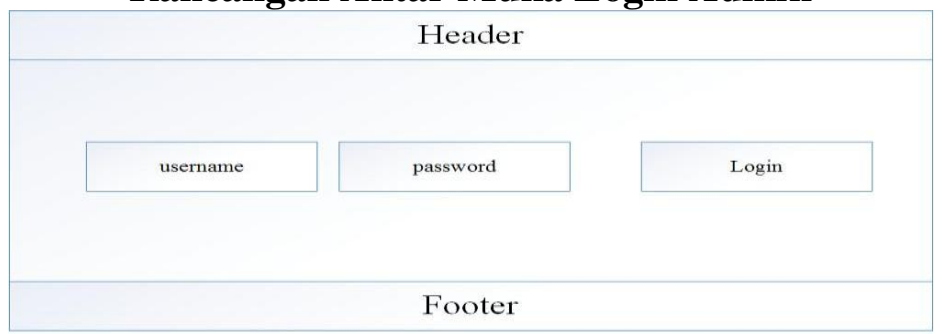

2) Rancangan Halaman Beranda Admin

Gambar 2

Rancangan Halaman Beranda Admin

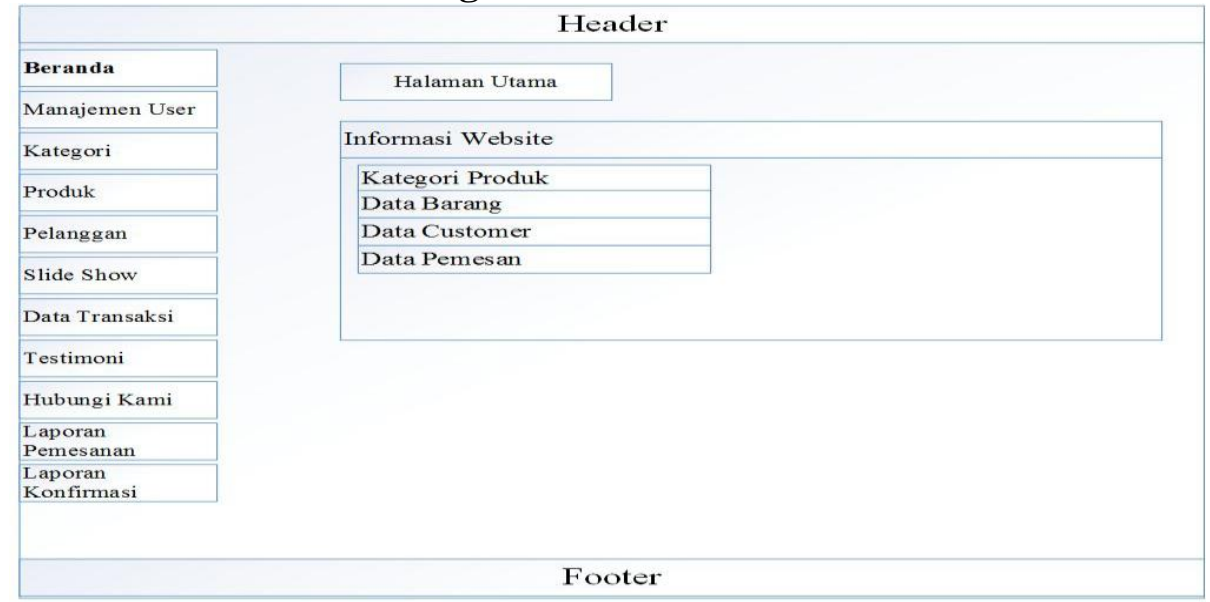

3) Rancangan Halaman Manajemen Admin

Gambar 3

Rancangan Halaman Manajemen Admin

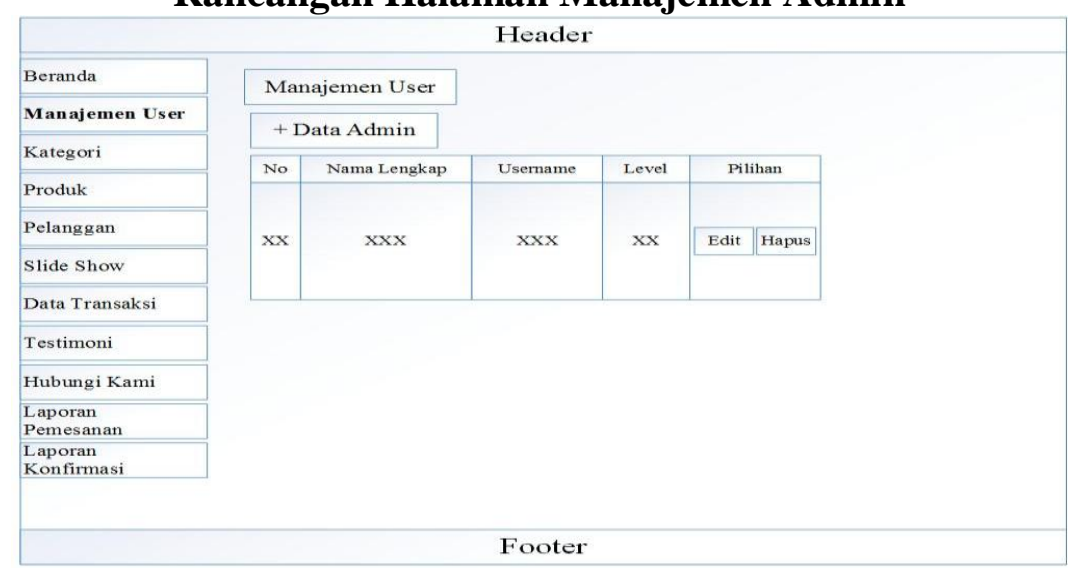


Dedi Saputra, Riswandi dan Setiaji

4) Rancangan Halaman Data Kategori

Gambar 4

Rancangan Halaman Data Kategori

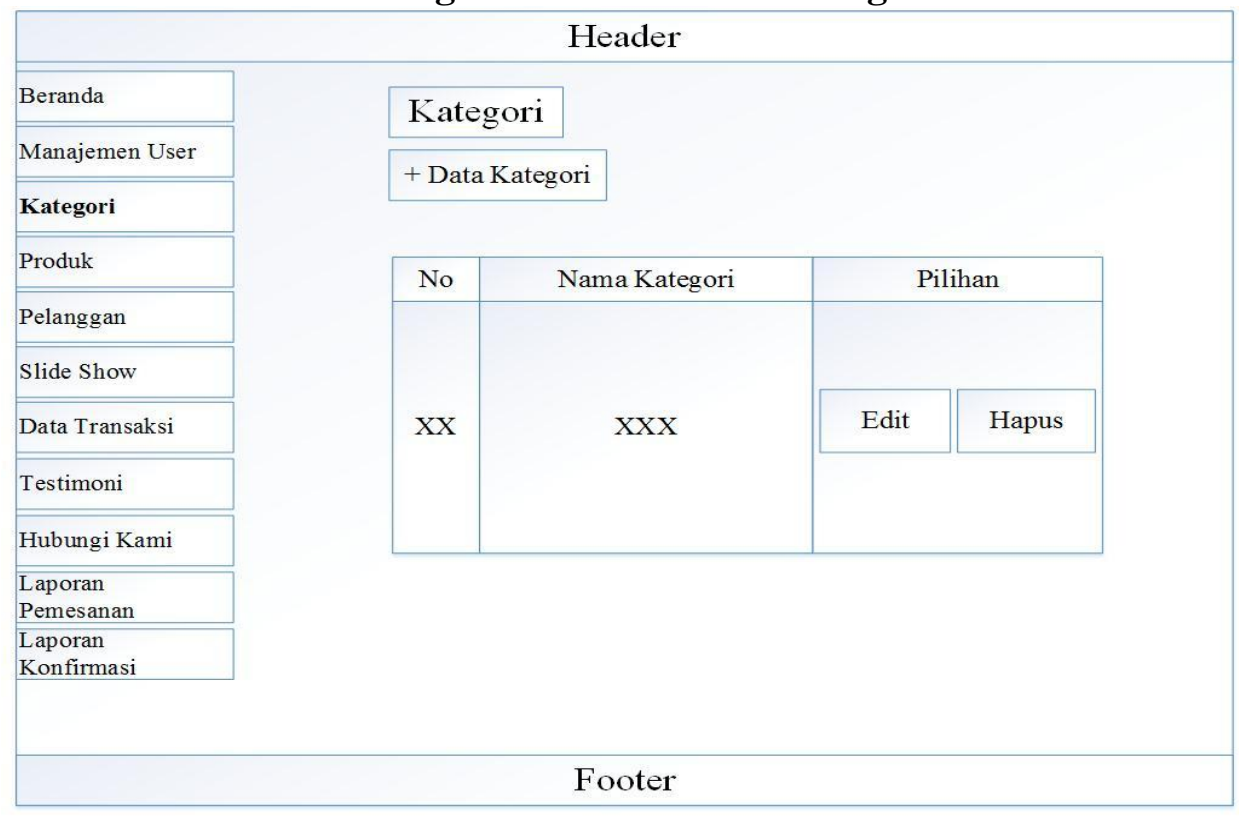

5) Rancangan Halaman Data Produk

Gambar 5

Rancangan Halaman Data Produk

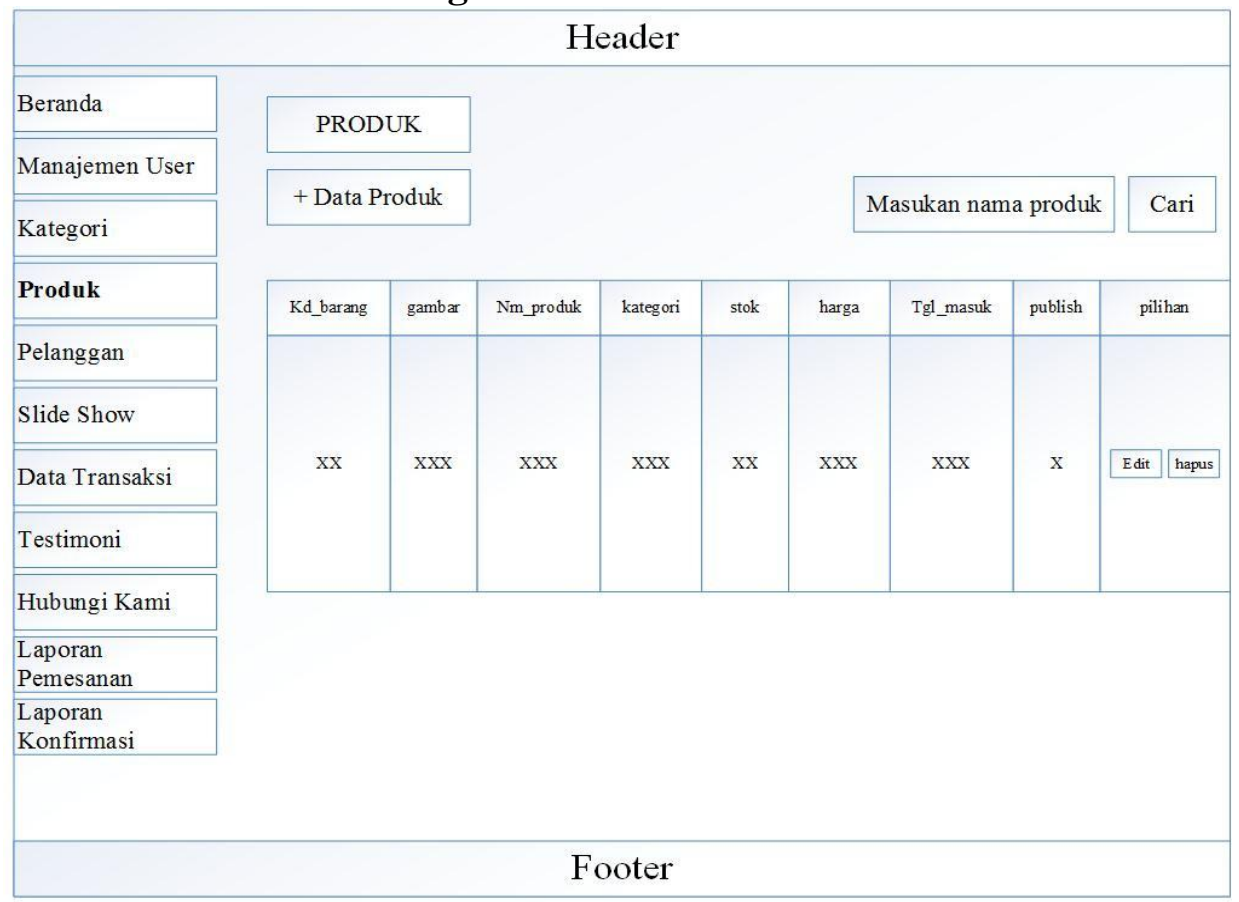


6) Rancangan Halaman Data Pelanggan

Gambar 6

Rancangan Halaman Data Pelanggan

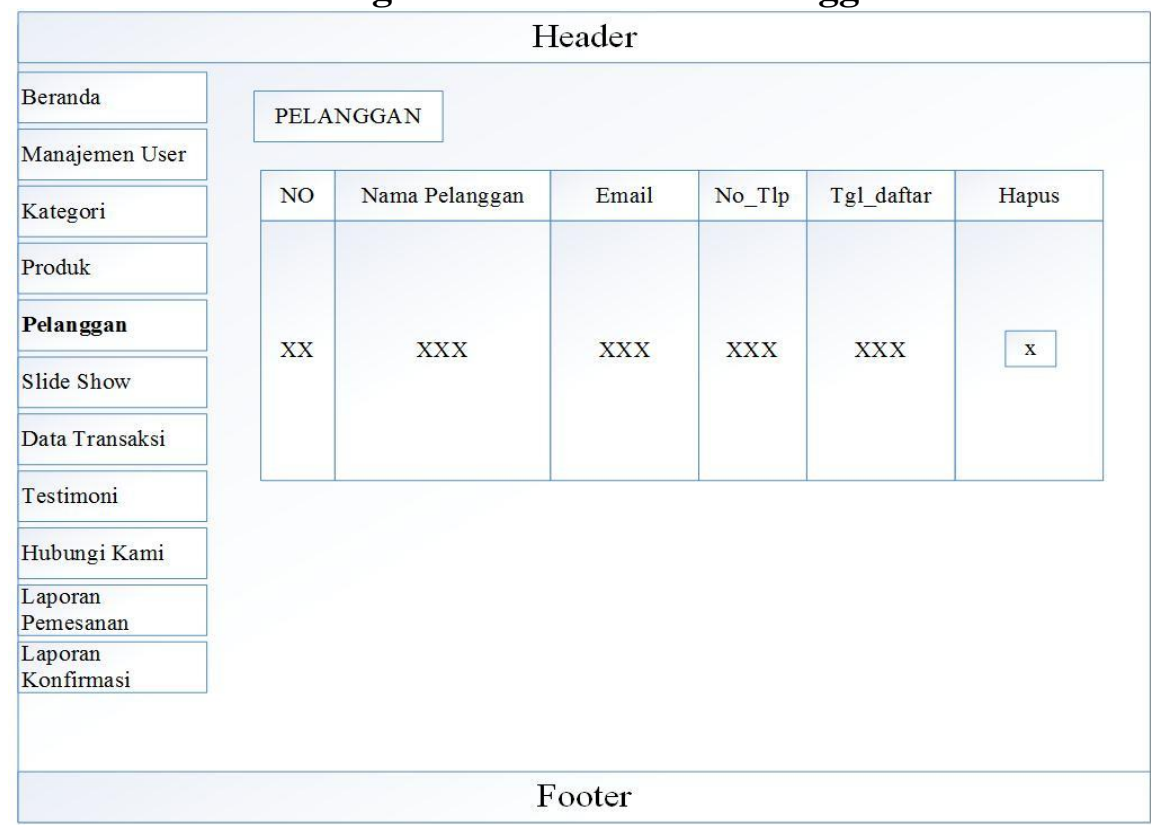

7) Rancangan Halaman Laporan Pemesanan

Gambar 7

Rancangan Halaman Laporan Pemesanan

\begin{tabular}{|c|c|c|c|c|c|c|c|}
\hline \multicolumn{8}{|c|}{ Header } \\
\hline Beranda & \multicolumn{3}{|c|}{ Laporan Pemesanan } & \multirow{3}{*}{ cari } & & & \\
\hline Manajemen User & \multicolumn{2}{|c|}{$\mathrm{Mm} / \mathrm{dd} /$ yyyy } & $\mathrm{Mm} / \mathrm{dd} /$ yyyy & & & & \\
\hline Kategori & & & & & \multirow[b]{2}{*}{$\begin{array}{c}\mathrm{Nm} \\
\text { Penerima }\end{array}$} & \multirow[b]{2}{*}{ Jumlah } & \multirow[b]{2}{*}{ Tota } \\
\hline Produk & \multirow{5}{*}{$\mathrm{xx}$} & No Pesan & Nama Barang & Tg1 Pesan & & & \\
\hline Pelanggan & & & & & & & \\
\hline Slide Show & & & & & & & \\
\hline Data Transaksi & & $\mathrm{xxx}$ & $\mathrm{xxx}$ & $\mathrm{xxx}$ & $\mathrm{xxx}$ & $\mathrm{xxx}$ & $\mathrm{xxx}$ \\
\hline Testimoni & & & & & & & \\
\hline \multicolumn{8}{|l|}{ Hubungi Kami } \\
\hline \multicolumn{8}{|l|}{$\begin{array}{l}\text { Laporan } \\
\text { Pemesanan }\end{array}$} \\
\hline \multicolumn{8}{|l|}{$\begin{array}{l}\text { Laporan } \\
\text { Konfirmasi }\end{array}$} \\
\hline \multicolumn{8}{|c|}{ Footer } \\
\hline
\end{tabular}

\section{b. Basis Data}

Berikut penggambaran basis data yang digunakan agar website ecommerce ini dapat di aplikasikan dengan baik. Di antaranya: 
Dedi Saputra, Riswandi dan Setiaji

1) ERD (Entity Relationship Diagram)

Gambar 8

Entity Relationship Diagram

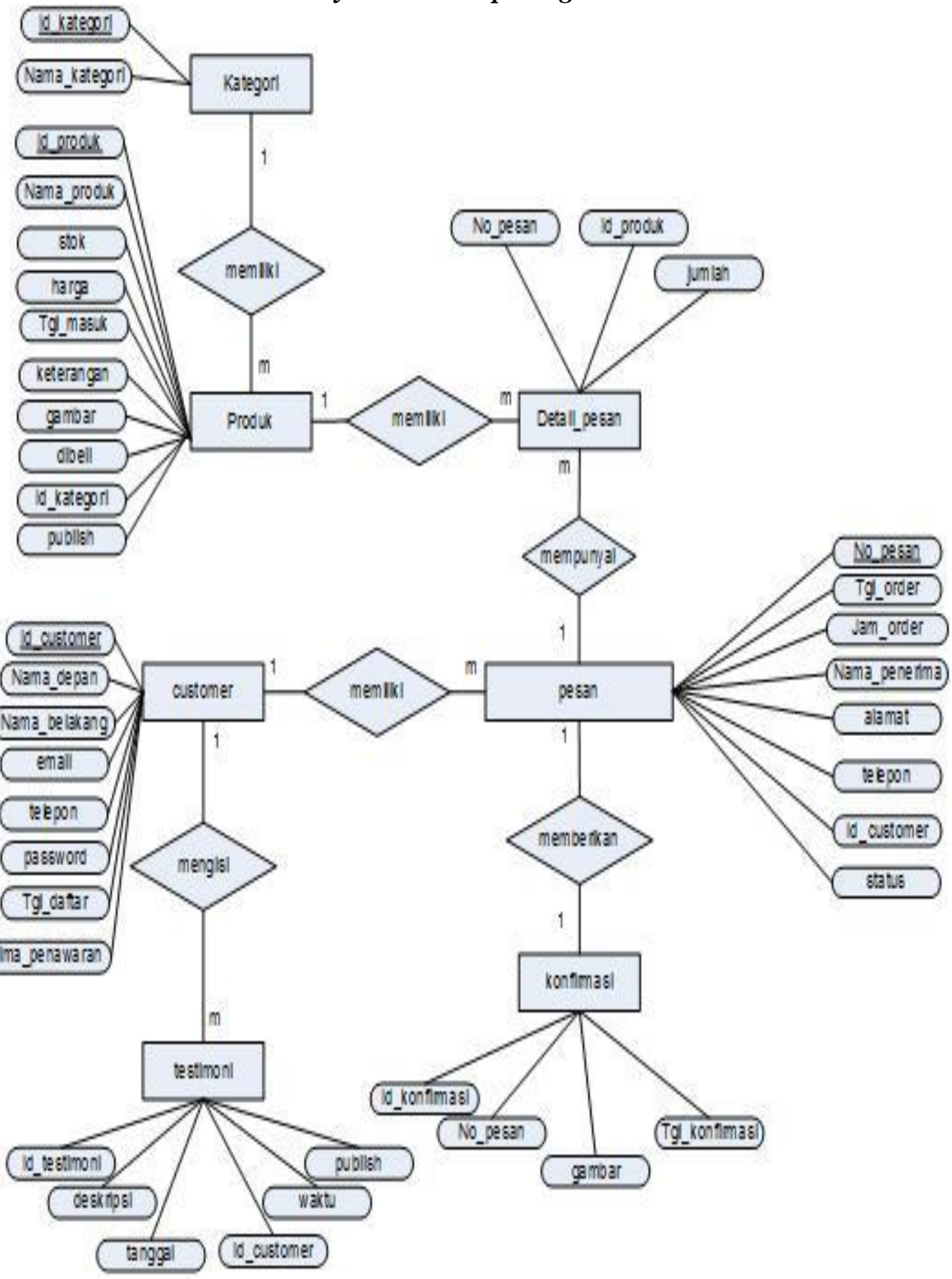


2) Logical Relational Structure (LRS)

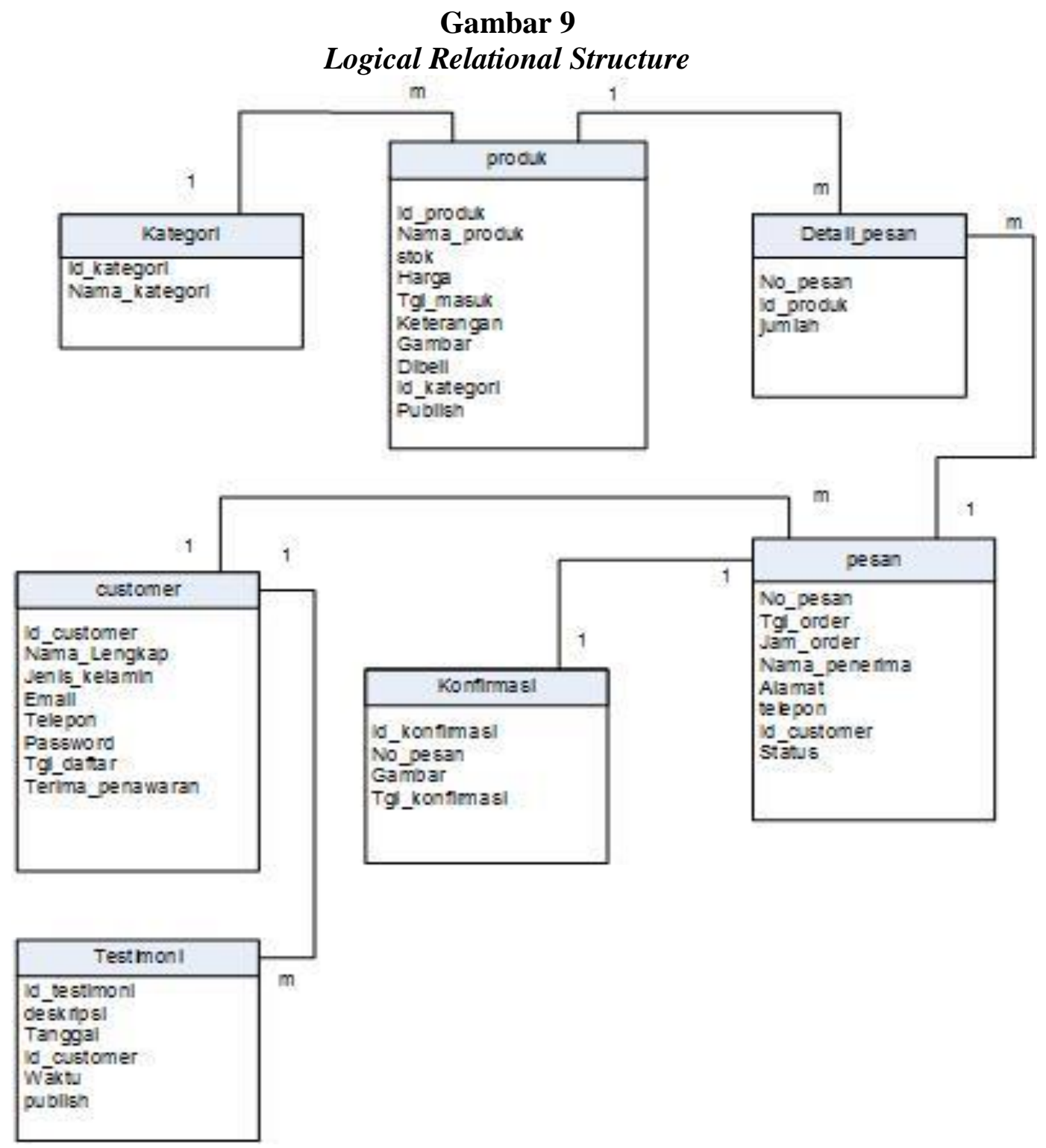

3) Spesifikasi File

Dalam pembuatan program ini penulis menggunakan satu buah file database dengan nama db_miniatur, didalam database tersebut terdapat beberapa tabel, adapun yang penulis tampilkan disini adalah beberapa sampel tabel tersebut sebagai berikut:

a) Spesifikasi File admin

$\begin{array}{ll}\text { Nama File } & \text { : Admin } \\ \text { Akronim } & : \text { Admin,myd } \\ \text { Fungsi } & : \text { menyimpan data password dan user name admin } \\ \text { Tipe File } & : \text { file master }\end{array}$


Dedi Saputra, Riswandi dan Setiaji

Organisasi File : Indexed Sequential

Akses File : random

Media : harddisk

Panjang Record : 104 karakter

Tabel 1

Spesifikasi File Admin

\begin{tabular}{|c|c|c|c|c|c|}
\hline No & $\begin{array}{l}\text { Nama } \\
\text { Field }\end{array}$ & Akronim & Tipe & Size & Keterangan \\
\hline 1. & Id Admin & Id_admin & Integer & 4 & $\begin{array}{c}\text { Primary } \\
\text { Key }\end{array}$ \\
\hline 2. & User name & Username & Varchar & 10 & \\
\hline 3. & Password & Password & Varchar & 50 & \\
\hline 4. & $\begin{array}{l}\text { Nama } \\
\text { Lengkap }\end{array}$ & Nama_lengkap & Varchar & 30 & \\
\hline 5. & Level & Level & Varchar & 10 & \\
\hline
\end{tabular}

b) Spesifikasi File Customer

Nama File : Customer

Akronim : Customer,myd

Fungsi : Untuk menyimpan data customer

Tipe File : file master

Organisasi File : Indexed Sequential

Akses File : random

Media : $\quad$ harddisk

Panjang Record : 115 karakter

Kunci Field : id_customer

Software : : mysql

Tabel 2

Spesifikasi File Customer

\begin{tabular}{cccccc}
\hline No & Nama Field & Akronim & Tipe & Size & Keterangan \\
\hline 1. & Id customer & id_customer & Varchar & 4 & Primary Key \\
\hline 2. & Nama lengkap & nama_lengkap & Varchar & 10 & \\
\hline 3. & Jenis Kelamin & Jenis_kelamin & Varchar & 6 & \\
\hline 4. & Email & Email & Varchar & 30 & \\
\hline 5. & Password & Password & Varchar & 50 & \\
\hline 6. & Telepon & Telepon & Integer & 13 & \\
\hline 7. & Tanggal Daftar & tgl_daftar & Date & - & \\
\hline & Terima & & & & \\
8. & penawaran & terima_penawaran & Integer & 2 & \\
& & & & &
\end{tabular}


c) Spesifikasi file detail_pesan

Nama File : detail_pesan

Akronim : detail_pesan,myd

Fungsi : sebagai tempat jual beli suatu barang

Tipe File : file master

Organisasi File : Indexed Sequential

Akses File : random

Media : : harddisk

Panjang Record : 15 karakter

Kunci Field : :

Software $\quad:$ mysql

Tabel 3

Spesifikasi File detail_pesan

\begin{tabular}{cccccr}
\hline No & Nama Field & Akronim & Tipe & Size & Keterangan \\
\hline 1. & No pesan & no_pesan & Varchar & 6 & \\
\hline 2. & Id produk & id_produk & Varchar & 6 & \\
\hline 3. & Jumlah & Jumlah & Integer & 3 & \\
\hline
\end{tabular}

d) Spesifikasi File Pesan

Nama File : pesan

Akronim : pesan,myd

Fungsi : sebagai tempat jual beli barang

Tipe File : file master

Organisasi File : Indexed Sequential

Akses File : random

Media : harddisk

Panjang Record : 63 karakter

Kunci Field : no_pesan

Software : : mysql 
Dedi Saputra, Riswandi dan Setiaji

Tabel 4

Spesifikasi File Pesan

\begin{tabular}{llllcl}
\hline No & \multicolumn{1}{c}{ Nama Field } & \multicolumn{1}{c}{ Akronim } & Tipe & Size & Keterangan \\
\hline 1. & No pesan & no_pesan & Varchar & 6 & Primary Key \\
\hline 2. & nama_penerima & nama_penerima & Varchar & 30 & \\
\hline 3. & Alamat & Alamat & Text & - & Primary Key \\
\hline 4. & Telepon & Telepon & Varchar & 13 & \\
\hline 5. & Id costumer & id_customer & Integer & 4 & \\
\hline 6. & Tgl order & tgl_order & Date & - & \\
\hline 7. & Jam order & jam_order & Time & - & \\
\hline 8. & Status & Status & Varchar & 10 & \\
\hline
\end{tabular}

\section{c. Rancangan Struktur Navigasi}

1) Struktur Navigasi Halaman admin

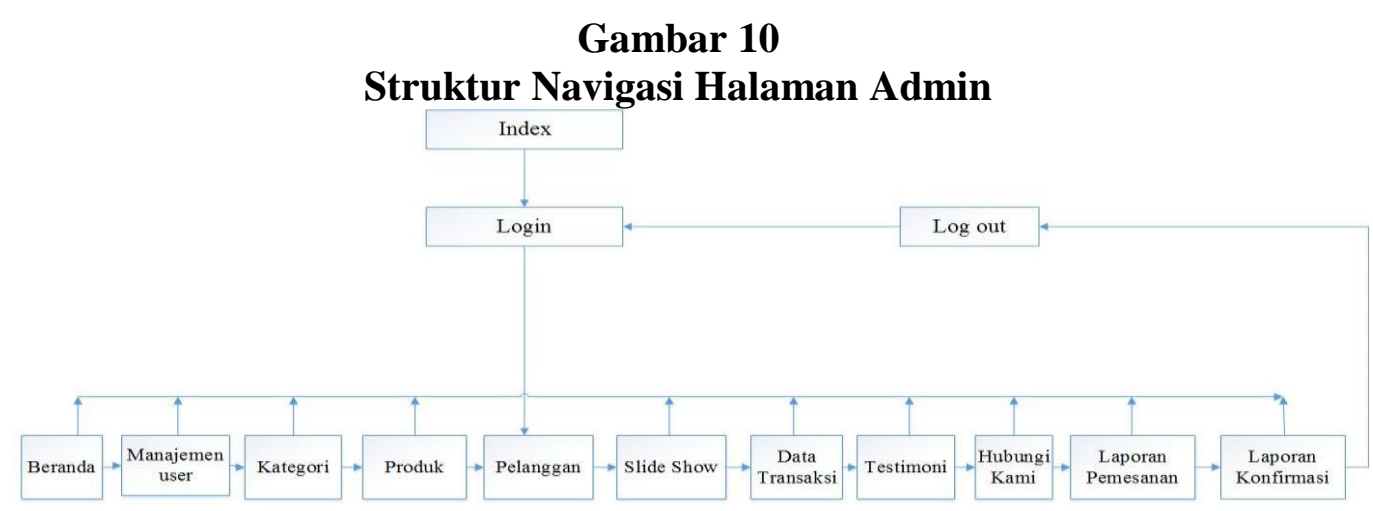

2) Stuktur Navigasi Halaman User

Gambar 11

Stuktur Navigasi Halaman User

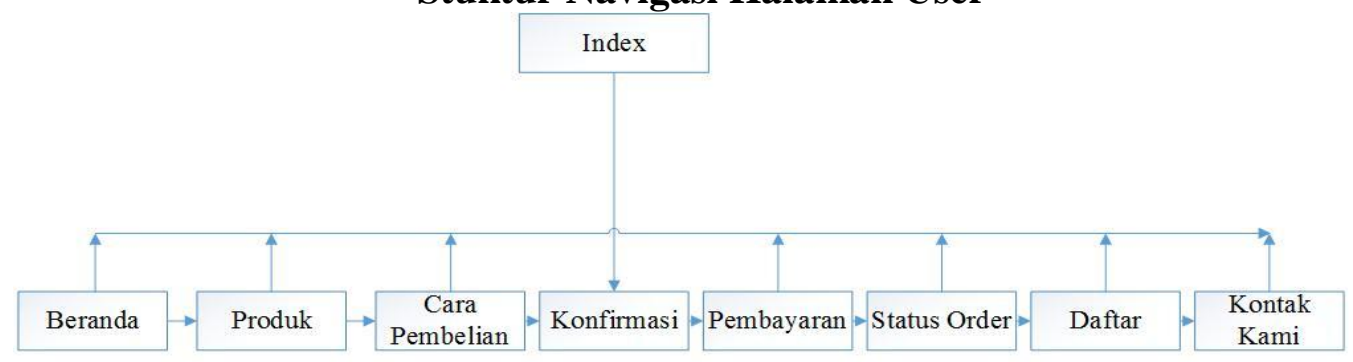


3) Struktur Navigasi Halaman Member

Gambar 12

Struktur Navigasi Halaman Member

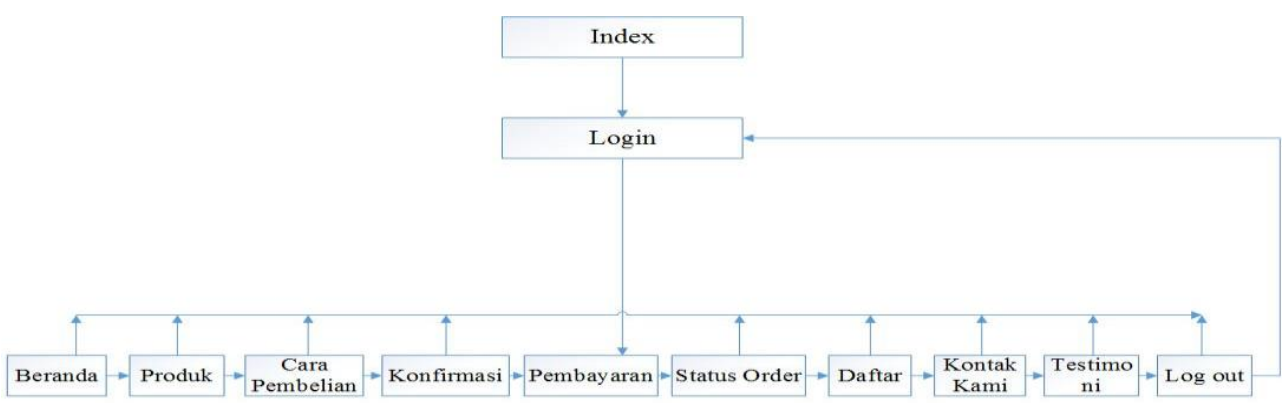

\section{Implementasi}

Dalam jurnal kali ini penulis hanya menyajikan beberapa sampel implementasi yang dibuat, untuk lebih lengkapnya ada di projek implementasinya. Berikut beberapa implementasi yang ditampilkan:

a. Implementasi Rancangan Antar Muka

\section{1) Halaman Login Admin}

Administrator harus melakukan login dahulu untuk memasuki ruang admin.

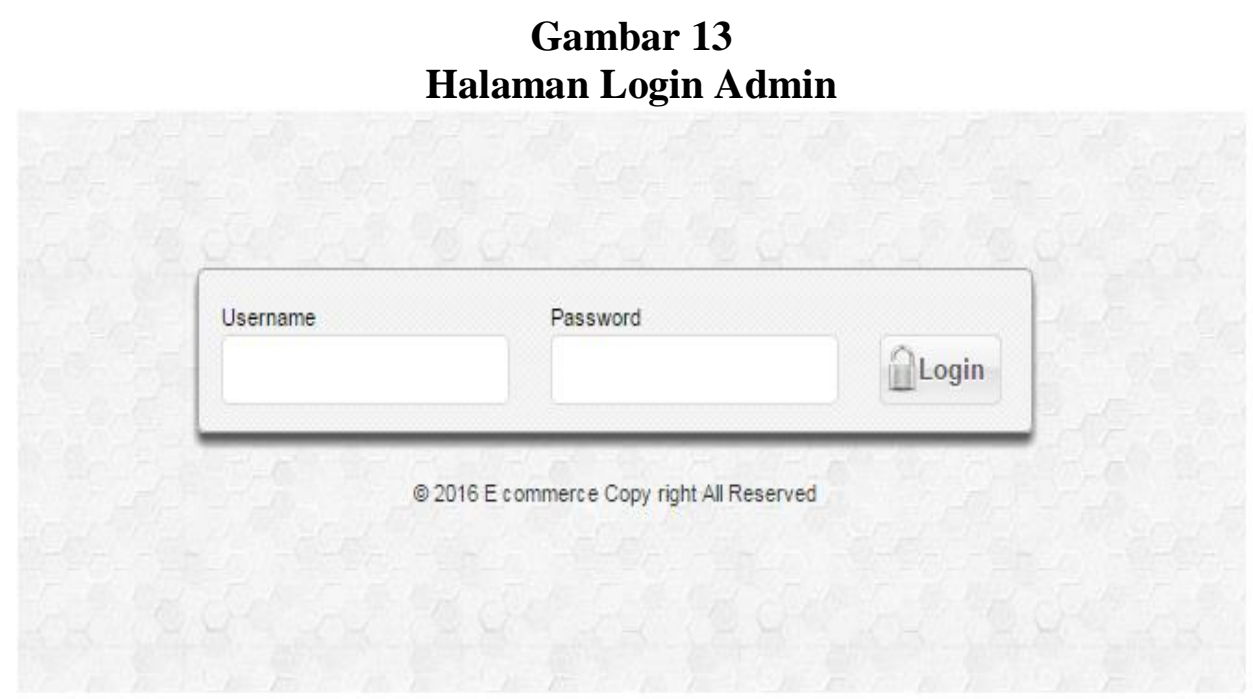

\section{2) Halaman Beranda Admin}

Pada halaman ini admin dapat menambah, mengdit, menghapus data yang terdapat didalam admin ini. 
Dedi Saputra, Riswandi dan Setiaji

Gambar 14

Halaman Beranda Admin

\begin{tabular}{|c|c|}
\hline i: Amianla & \multirow[t]{2}{*}{ " HALAMAN UTAMA } \\
\hline :: Marą, & \\
\hline : Kategcri & In'ormes Wets te \\
\hline ï PItd.jk & \multirow{8}{*}{$\begin{array}{l}\text { (5) Kateoori Produk } \\
\text { (8) Data Dareno } \\
\text { (5) Data Customer } \\
\text { (9) Data Pe mesanar }\end{array}$} \\
\hline : Pclancaan & \\
\hline ii Plde stron & \\
\hline$:=$ [a: & \\
\hline \# Testimori & \\
\hline 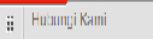 & \\
\hline :" Laporan Perressanan & \\
\hline \# Laporen Kcnirnasi & \\
\hline
\end{tabular}

\section{3) Halaman Manajemen User}

Pada halaman ini admin dapat menambah, mengdit, menghapus data yang terdapat didalam admin ini.

Gambar 15

Halaman Manajemen User

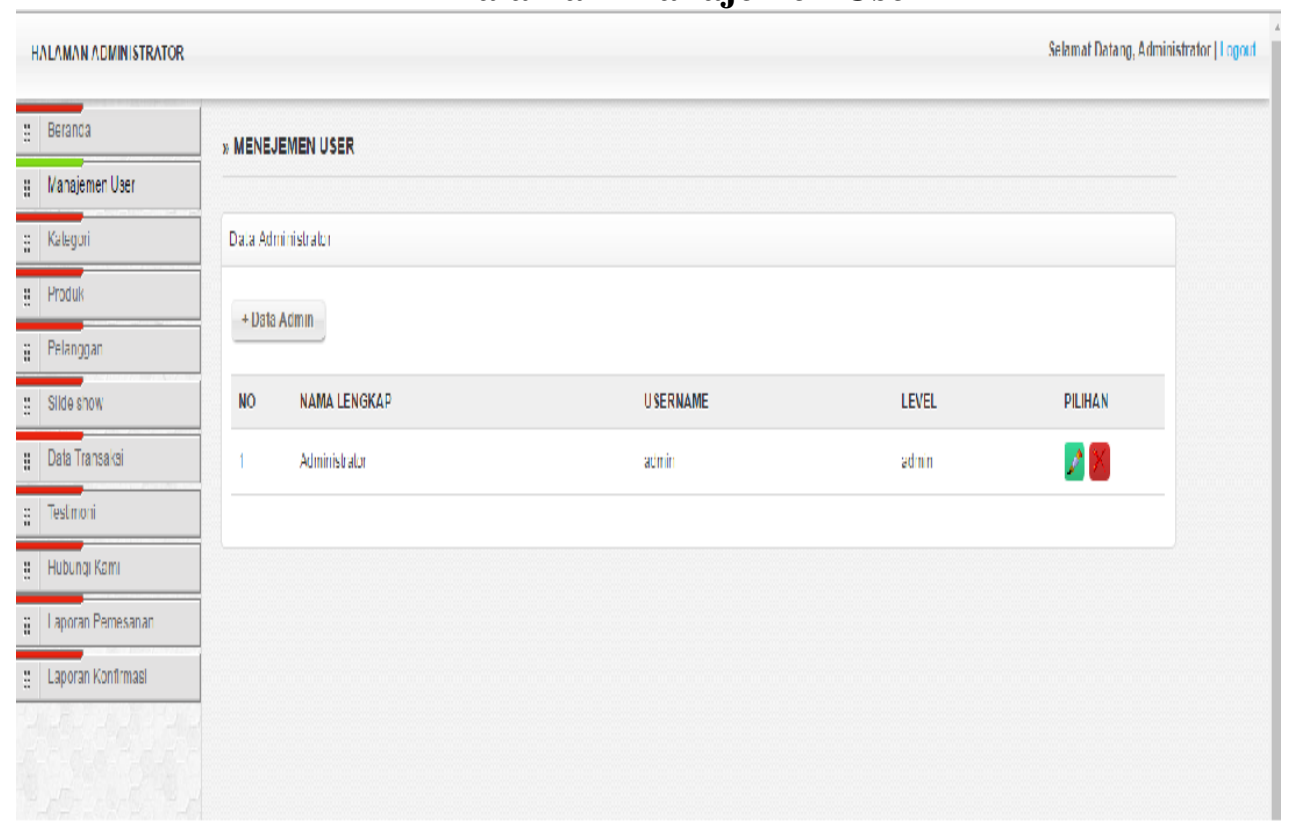

\section{4) Halaman Data Transaksi}

Pada halaman ini admin dapat melihat, mengedit atau menghapus detail data transaksi pemesanan. 
Perancangan Website E-Commerce Sebagai Media Penjualan Miniatur Bus

Gambar 16

Halaman Data Transaksi

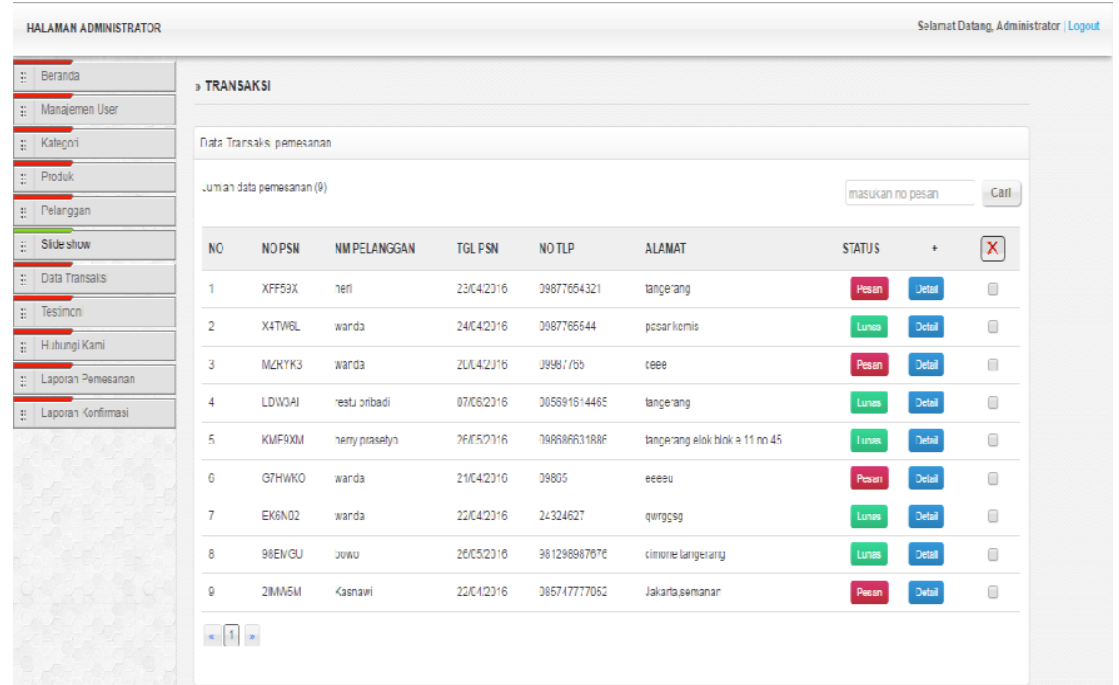

5) Halaman Beranda

Pengunjung akan melihat tampilan awal yang ada di website penjualan miniatur bus.

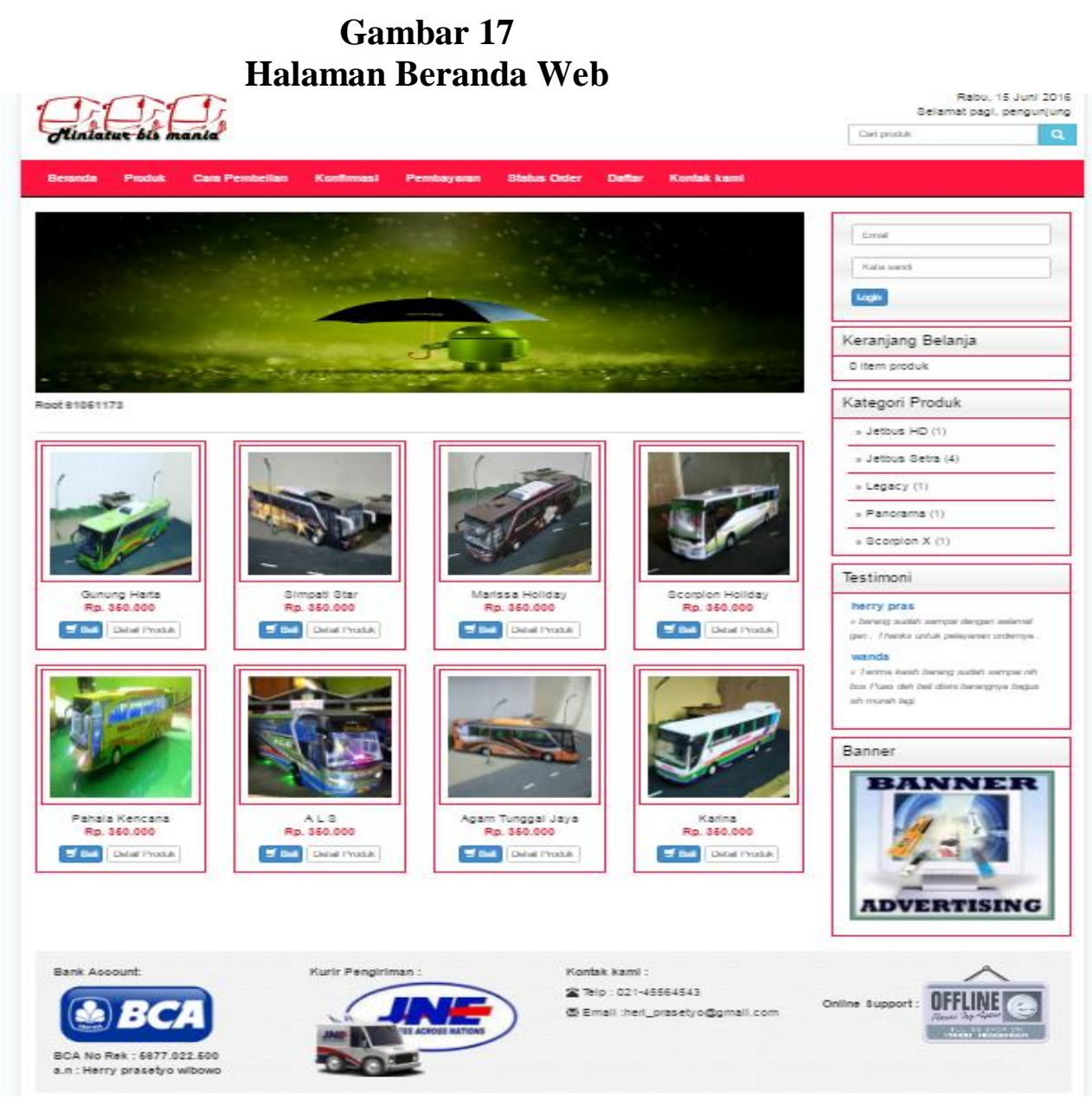


Dedi Saputra, Riswandi dan Setiaji

\section{b. Spesifikasi Sistem Komputer}

1) Perangkat Keras (Hardware)

Pada perancangan website untuk took miniatur bus, penulis menggunakan komputer dengan spesifikasi seperti dibawah ini:

$\begin{array}{ll}\text { Microprocessor } & : \text { AMD DUAL, CORE Processor } 1,3 \mathrm{Ghz} \\ \text { Memory Size } & : 2,00 \mathrm{~GB} \text { RAM } \\ \text { Monitor } & : 14 \text { " } \\ \text { Hard Disk } & : 500 \mathrm{~GB} \\ \text { Keyboard } & : 86 \text { Keys } \\ \text { Mouse } & : \text { Standard Mouse } \\ \text { Printer } & : \text { HP Deskjet }\end{array}$

2) Perangkat Lunak (Software)

Adapun software yang digunakan selama perancangan website adalah:

$\begin{array}{ll}\text { Sistem Operasi } & : \text { Windows } 2010 \\ \text { Program aplikasi Desain } & : \text { Adobe Photoshop CS6, Adobe } \\ & \text { Dreamweaver CS5 } \\ \text { Bahasa Script } & : \text { PHP, MYSQL } \\ \text { Web Server } & : \text { XAMPP } \\ \text { Web Pengunjung } & : \text { Google Chroom } \\ \text { Database } & : \text { PHP myadmin }\end{array}$

\section{Kesimpulan}

1. Dengan adanya website ini, informasi yang dibutuhkan oleh masyarakat luas dapat di akses dengan cepat dan mudah.

2. Dengan menggunakan website ini, mampu memberikan informasi lebih lengkap secara efisien waktu dan biaya.

3. Dengan menggunakan website ini, toko dapat melakukan transaksi bisnis dan juga sebagai sarana untuk promosi dan pemasaran 
Perancangan Website E-Commerce Sebagai Media Penjualan Miniatur Bus

\section{BIBLIOGRAFI}

Cahyono, A. B. (2016). Perancangan Sistem Informasi Penjualan Arloji Berbasis Web.

Ellyani, W., \& Sari, D. R. (2016). Perancangan E-Commerce Sebagai Media Pemasaran Mengunakan Metode Customer Relationship Management (CRM) Pada Rainbowtik Pangkalpinang.

Manan, H. A., SH, S., \& Hum, M. (2017). Hukum Ekonomi Syariah: Dalam Perspektif Kewenangan Peradilan Agama. Prenada Media.

Pramadita, I. (2017). Embedded Graphic Online Service. Syntax Literate; Jurnal Ilmiah Indonesia, 2(1), 14-20.

Sutarman, M. (n.d.). Kom. 2009.“pengantar teknologi informasi”, Edisi pertama. Bumi Aksara. Jakarta. 